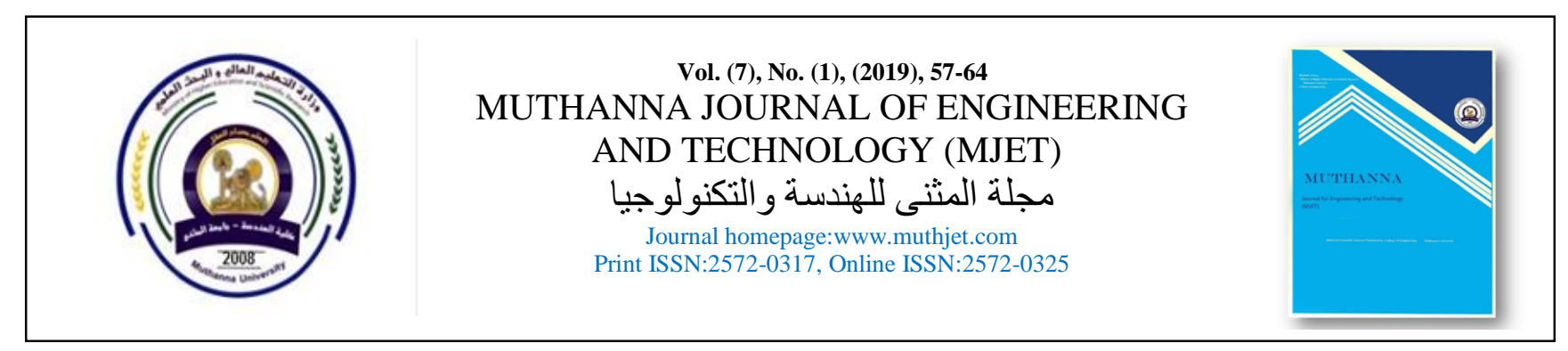

\title{
Urban Visual Quality Of Traditional Kut City Center
}

\author{
Hussam S. O. Aldelphi \\ Wasit University- Eng. College / Department of architecture -Iraq
}

\section{ARTICLE INFO}

Received: 01/01/2019

Accepted: 18/09/2019

\section{Keywords}

Visual Quality, quality of life, urban identity, Traditional City, Alkut City Center.

\begin{abstract}
This paper addresses of urban visual quality at Traditional Kut City Center as an important part of urban life concept. Where most of the traditional city centers suffer from unorganized interventions and urban disruption, affecting the identity and future of the city and its quality of urban life. To achieve the objectives of this paper, the study area was divided into three main areas: the river side, the middle part, and the part overlooking the residential units. A quantitative analysis of the city center (the three parts) was prepared and analyzed using the SWAT method.

A questionnaire was prepared and answered by a group of experts with expertise and specialization in the field of urban design and architecture to answer the set of axes allocated to the questionnaire. The research found that there is a positive correlation between these indicators. The more attention is paid to the visual urban image indicators of the traditional city center, the clearer the urban environment will be, thus increasing the city's visual value and quality of life.

To improve the urban visual quality at Traditional Kut City Center, the research considers the need to attention of three vertical indicators, and look at to urban sustainability as an important part of enhancing the visual quality of the city center, where sustainability works with visual quality first by determining the standards of construction and urban intervention of The traditional city of Kut, And secondly, the morphological formation of the traditional center which is the main factor in the concept of enhancing the visual quality of urban centers in the cities.
\end{abstract}




\section{Introduction}

Modern urban design in traditional city centers deals with the quality of life in a new way by imposing restrictions that are sometimes stringent, To develop communities to serve the needs of people in the urban environment to achieve the three ways of development that achieve the quality of urban life: public health, family, space. There are two basic ways to examine urban quality: the first includes urban quality control through a set of indicators that come from spatial data collected using official sources or restrictions, The other method is field survey and direct observations, And the adoption of expert opinion in the development of the traditional urban environment of the city.

Quality of life refers to daily life promoted by healthy food, clean air and water, good infrastructure, open spaces, conservation of natural resources, security from crime, protection against radiation and toxic substances. Quality of life is an important part of urban quality in the traditional urban environment in which we live and interact with. The term urban quality describes some physical and moral characteristics that reflect the amount of interaction and personal satisfaction and our appreciation of where we live. This introduction indicates how we should deal with our built environment and the standards adopted in the industry Visually and provide the place as an integral part with the quality of the place.

\section{Methodology}

There are many factors that affect visual quality. Therefore, survey tools were manufactured with each factor being considered as a set of components that in turn contain their own tools. The methodology proposed in this research focuses on the expertise and competencies of the evaluators in the evaluation. The expert questionnaire for visual quality measurement was designed by developing three alternatives to answer each statement: (yes, almost, no).

To achieve the objectives of this paper, the study area was divided into three main areas: the river side, the middle part, and the part overlooking the residential units. A quantitative analysis of the city center (the three parts) was prepared and analyzed using the SWAT method. A questionnaire was then prepared and answered by a group of experts with expertise and effectiveness in urban design and architecture.

The research indicators were divided into vertical indicators (visual identity, Mental image, Sense of place) and horizontal indicators (Maintenance and maintenance, Enhancement of visual value, innovation \& Urban innovation) in order to measure the relationship between them and determine the visual value of Traditional AlKut City Center. The adoption of established criteria, the use of evidence, tools and group discussions illustrate the final terms of the paper.

\section{Quality of City}

The concept of City quality according to the UN quality-of-life refers to seven main dimensions: economic, political, physical, environmental, mobility or urban social or psychological quality. [1] These dimensions vary according to the nature of places and communities. The city at Camillo Sitte is a civil art, and the visually organized city is the expression of the life of society. [2]

urban city quality is defined as a complex and multidimensional concept. Can be defined in terms far broader than the physical characteristics of buildings, spaces and street patterns, a concept that connects society to the place. [3]

The concept of city quality will be explained in the next paragraph:

\section{City and Urban Design Values}

The city is the art of making people, referring to different projects, products and processes and overlapping with (property ownership, development processes). [4] Today's cities are not created by chance, but as a result of the individual and collective decisions accumulated by engineers, surveyors, lawyers, investors and architects, all of whom are unique in making their decisions for logical reasons. [5] Consequently, their decisions affect the quality of the physical entity of the city and its visual quality.

The city cannot be built according to unilateralism theory (Is any doctrine that supports unilateral action.), it is the formation of several parts locally located in the changing processes of formation. The city becomes a Visual icon references to the historical phase and social changes, and interconnect the parts of the city among them to define the concept of spatial structure. here, the mental schemes of individuals play an important role in Understanding and understanding the system of relations of the components of the city gives a sense of place. see Figure (1)

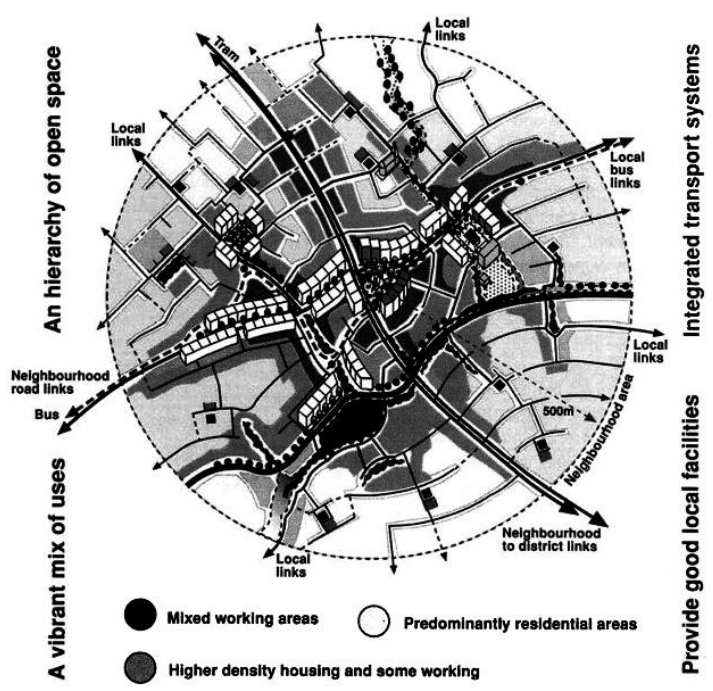

Figure (1) The key components of a mixed-use and integrated neighborhood proposed. 
This process plays a role in the formation of mental schemas, and represents part of the personal experience or experience of the group that constitute the collective memory. then, basic function in the composition of cities remain immobile in effectiveness Dynamic city (momentum in the city). [6] As Kevin A. Lynch said: "The design of the city should not be used solely for the architect's opinion, but it is necessary to do a survey of the opinions of all the people".[7] All of them are involved in the design and the gathering of ideas and it is necessary to gather ideas from all people so that they can coexist with urbanization.

The process of assessing the visually constructed environment has become an important factor in the improvement and development of the urban environment as an important tool in guiding interventions in the urban fabric.

\section{Quality Of Urban Life}

Measuring the progress of societies based on the quality of life and the decent living of citizens as a supplement to traditional economic and social indicators is today an expression of the emergence of a new model of development that places decent living for citizens at the center of its concerns. [8] There are many global indicators that measure the quality of life in many ways, including:

The World Classification of Livelihoods: cities are classified in 140 countries according to the quality of urban life based on the assessment of stability, environment, health care, education, sports, culture, infrastructure, etc. [9] Mercer Quality of Life Index: classified cities according to the following aspects: transportation, political, social and cultural environment, public services, health, economic environment, schools, education, natural environment, housing, global facilities, theaters, cinemas, sports, consumer goods, restaurants and recreation. [10]

Monocle's list of lifestyle: An annual list of 25 of the world's best living cities. The assessment is based on the following aspects: global communication, environmental issues, access to natural places, architectural quality, urban design, health care, business environment, crime, security, culture, restaurants, tolerance and policy development. The OECD Quality of Life Index: An indicator that compares the quality of life among countries based on eleven aspects of the Organization's view: security, health, income, employment, balance between life, work, education, level of satisfaction, housing, environment, society and civic participation. [11]

ARRP Quality of Living: a unique initiative by the Policy Public Institute to measure the quality of life in American communities based on the following aspects: transport, health, economy, education, housing, residential neighborhoods, environment, community participation and equal opportunities. [12]
As we see, among the indicators of quality of life, there are indicators related to the urban aspect, Many of the traditional urban streets around the world have become visual chaos, and functional incompatibility of visual quality. There is recognition of the effects of urban life on physical and mental health. This is why we need to examine the visual urban quality, especially in traditional city centers

\section{Urban Visual Quality}

In our modern cities we have lost the traditional vision of urban space. The reason for this loss is the lack of understanding of what this means in the urban structure.[13] The traditional city has grown according to the process of forming a continuous, organic and contemporary city that interacts with and interacts with it.[14] The question is, does the shape of the city's parts affect the quality of life there?

Therefore, Visual quality is in conformity with certain requirements or specifications, it is the total characteristics and characteristics of a product or service that makes it capable of meeting certain needs. There are three major trends in urban visual quality study:

\section{1. visual identity:}

The phenomenon of "legibility" is related to the concept of Imageability. The ability to visualize "the possibility of evoking a strong imagination of individuals who can form "mental images" and clear the physical environment through the characteristic that give them a clear definition and strong composition influential". [15]

The phenomenon of clarity is achieved when the areas of the environment and their features and methods are easily defined, can be understood, organized and grouped together within a coherent and homogeneous plan that makes it easy for the users of the environment to sense the direction and find their way within it. [16] See Figure (2)

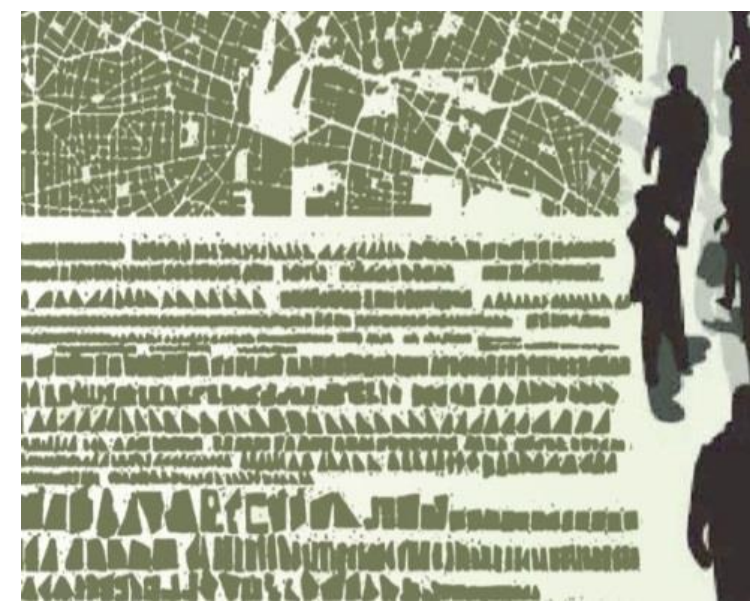

Figure (2) The Part of Traditional City

The question is, does the shape of the city's parts affect the quality of life there?

It was also agreed by many theorists and researchers that the phenomenon of clarity and its 
behavioral consequences of space guidance and finding the way in the built environment are essential factors for the efficient environment. [17] This theory holds that traffic systems and urban efficiency take precedence in the definition of outer space patterns. [18] From this urban designer, in his overall vision of urban design, he can connect the motor and the visual of the city user to the urban elements, rather than focusing on the space-based spatial scheme.

Seamless mobility is a new way of life that ensures the use of the surrounding environment and urban life, and a suitable alternative to movement in the short and medium distances in the city .Sensory information of the urban environment received from the ocean can affect the forms and density of communication and social interaction between the individual and the surrounding environment.

\subsection{Mental image:}

In his book The Image Of The City, Lynch's study is one of the most important cognitive studies that focused on identifying the city's mental image through place theory. [19] He drew his study to understand the formal structure of the city from an optical perspective, relying on the elements of the physical construction of the cities, and identified five types of elements that can be used by the individual to read the physical environment of the city. These types of elements that help to read the physical body of cities and make them more imaginable. In this theory, the focus is on urban sizes or what is called the negative space of architectural schemes within the third dimension (height) and the hierarchical relationships of interconnected spaces to illustrate the structure and system of urban spaces as basic parts of urban form.

The number of information can be determined from direct urban formalities that can contribute to assessing the impact of the nature and intensity of the complexity and diversity of environmental influences on the individual due to the negative perception of density The high sensuality resulting from the nature of relations between the components of urban form.

\subsection{Sense of place:}

The concept of belonging to place describes the relationship between man and place. When a person belongs to a certain place, he achieves an important psychological function that defines the spaceexistential boundaries of man and defines his relationship with his environment. The theory of place goes in that it adds elements of human requirements, cultural elements, and natural and historical contexts. [20] This theory is based on the existence of lines connecting space elements to each other, including pedestrian roads in the streets, open linear spaces and other elements that effectively connect parts of the city to each other.

The proponents of this theory are committed to enriching the tangible physical aspect of the building with the unique forms and details of the physical urban body. In this theory, emphasis is placed on the urban context and the linking of new designs to the existing context and the nature of the existing and surrounding conditions of the building or the urban body, especially in terms of the social, cultural and historical conditions of the place. As we see the Sense of place refers to the attention to different aspects of the urban environment, including Urban Visual Quality.

\section{AlKut City Center}

Most of the traditional cities centers are under great pressure as a result of urban interventions by individuals and institutions. These centers are threatened with harm, neglect and loss of architectural and urban characteristics, losses of identity and privacy. Most of these problems refer to interventions and land-use changes, as well as the tyranny of personal interests in the nature of these interventions at the expense of the integration of the urban landscape of the city. The traditional city center of Kut is one of those centers that suffer from deformity in the urban structure and a decrease in the visual quality of urban areas

\section{Traditional Kut City Center}

Kut is the center of the province of Wasit, one of the southern provinces of Iraq, located south of Baghdad, about $180 \mathrm{~km}$, and the city in the shape of a peninsula surrounded by the Tigris River on three sides, the line length 45 degrees 40 minutes and 32 degrees and 31 minutes, Al-Badra and south of AlHayy, is the largest city in Wasit province and occupies the 12th place in terms of population in Iraq.

There are overlapping city plans, building forms, and land uses, in a manner that is difficult to separate between its contents at the level of the city's temporal extension and the new changes occurring at the city level.

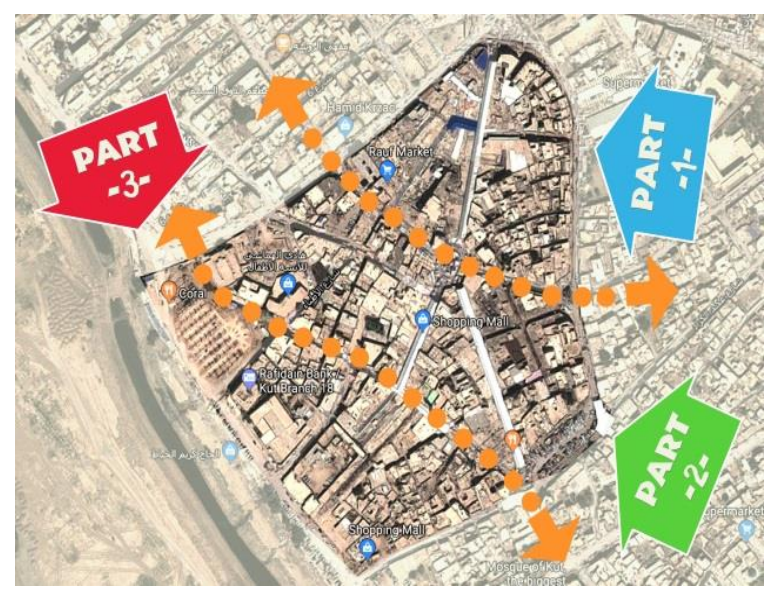

Figure (3) Traditional Kut City Center.

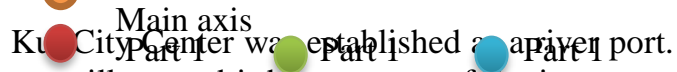
it was a village and it became one of the important river trade areas after a British company obtained the 
concession of running vessels between Baghdad and Basra in 1869. The population grew and the importance of Kut became more important. British troops surrounded Kut by General Townsend and his forces in World War I. General Townsend took his place from the house of Muhammad Ali Tabatabai, now near the Husayniyah Square in the city center. And The English graveyard remains in the city center so far.

In traditional Kut city center, economic and social initiatives often reinforce the morphological value of a city, These initiatives and improvements are effective tools in stopping some of the problems that accompanied the deterioration of these centers due to the time limitation and not keeping up with the technical and institutional progress of some of the traditional city centers in the developed countries.

The challenge of traditional neighborhood rehabilitation projects is to understand how to tackle the many problems without destroying their living culture, which is directly reflected in the nature of investment in infrastructure. Moral values in city centers include taking positions from the built environment and working within them in line with clear trends.

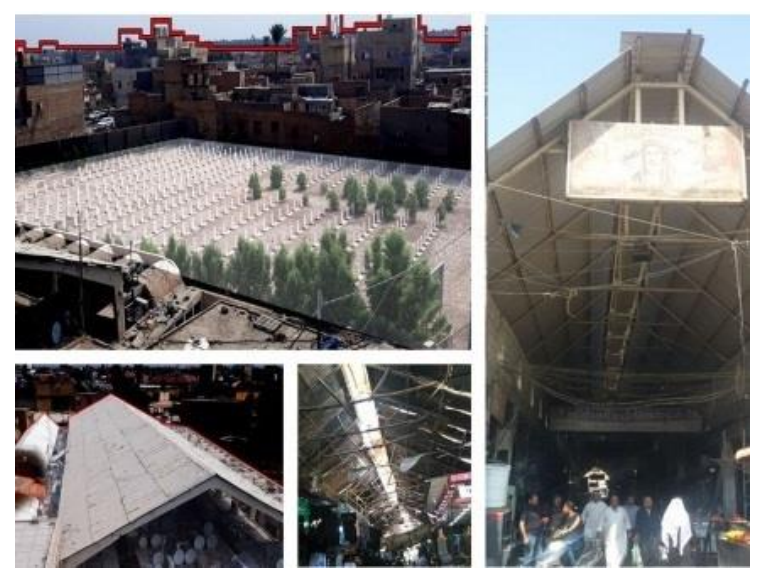

Figure (4) Traditional Kut City Center.

Economic power and individuals are not enough to improve the image, which is predicated on vision and strategic plans to improve the place and take care of the future of traditional kut city center. To achieve a good visual quality of the urban environment we must achieve three aspects and recommend that attention to them and those aspects are: Demonstrating traditional architecture in the spirit of integration with the foundations of the times, here we need to maintain important features in downtown Kut as in the house of Tauzand cemetery and others. and Demonstrate the spirit of the traditional kut city center with a contemporary flavor, and support innovative creative ideas that care about the spirit of the place and their support by the central government or open the field of investment in the traditional kut city environment.

\section{2. problem and Search goal}

The main search problem has been divided into three minor problems:

1. Lack of interest in urban visual quality of Traditional AlKut City Center.

2. Loss of control over the parties participating in the Traditional AlKut City Center (work individually).

3. Clarity of visual urban chaos in the Traditional AlKut City Center.

The research is based on three hypotheses:

1. Attention to urban visual quality can contribute to improving quality of life within the Traditional AlKut City Center.

2. Loss of urban identity by neglecting urban visual quality.

3. The implementation of indicators at different stages, including the design and implementation stages and the life cycle of the building in the urban context, can contribute to improving the urban existing of the Traditional AlKut City Center by focusing on urban visual quality.

The research aims to focus on the concept of urban identity as an important part of visual quality in urban areas and its role in improving the urban quality. As well as focus on the role of visual quality in the design, implementation and the life cycle of the building in the urban context as key indicators in improving the existing urban environment of the traditional city center of Kut.

\section{Research design}

The research is based on documenting the existing of the situation and the work of Swat in addition to relying on the opinions of experts in Developing assessment model of urban Environment and vision of old Kut city center future. By studying the case study and analyzing all its parts, we found that the selected area can be considered as a commercial area of $80 \%$ and residential $20 \%$, because most of the residential uses in the region have been transformed into commercial by virtue of its strategic location.

The majority of the commercial routes enjoyed by the region, in addition to the central markets and the presence of some important commercial buildings in the region, which qualify them to be commercial and mainly require consideration of this aspect. In developing research strategies, emphasis has been placed on sustainable human development, which must reflect people's own choices about how they live and their desire to improve their future in harmony with their environment.

\subsection{SWAT analysis of traditional kut city center}

The traditional Kut Center can be seen as a social and economic recovery project that goes beyond the environmental dimensions to provide the area with a green area, With the creation of jobs through the investment of cultural capital located in the region for the restoration and rehabilitation of historic buildings. 


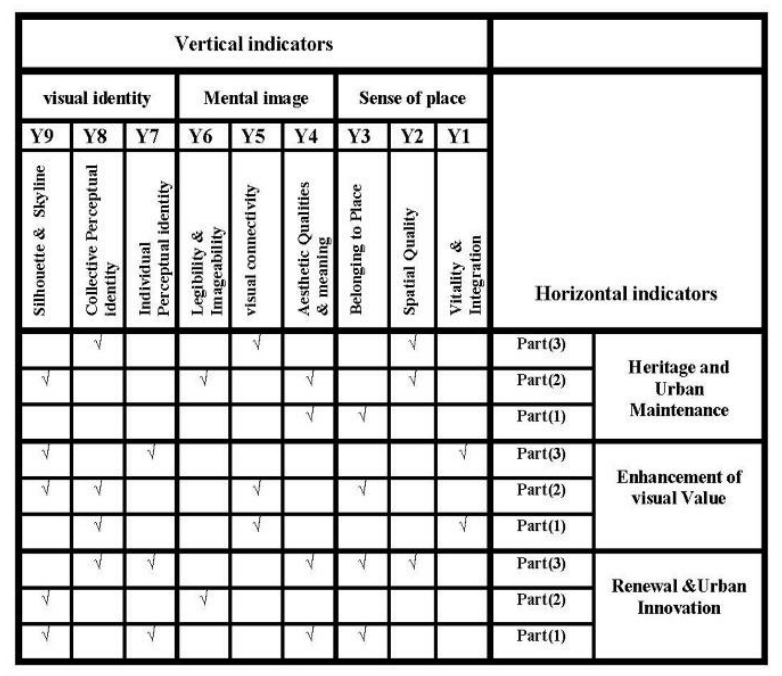

TABLE (1) Vertical \& horizontal indicators

\begin{tabular}{|c|c|c|c|c|}
\hline & main questions & Part 1 & Part 2 & Part 3 \\
\hline & & & & \\
\hline 1 & $\begin{array}{l}\text { Do you think that commitment to sustainable self- } \\
\text { development is important to activate the vitality } \\
\text { and integration of Traditional Kut City Center? }\end{array}$ & & & \\
\hline 2 & $\begin{array}{l}\text { Do you see the commitment to the active } \\
\text { participation of local communities as important to } \\
\text { the spatial quality of Traditional Kut City Center? }\end{array}$ & & & \\
\hline 3 & $\begin{array}{l}\text { Do you think that taking common responsibility is } \\
\text { important for activating belonging to the place at } \\
\text { the Traditional Kut City Center? }\end{array}$ & & & \\
\hline 4 & $\begin{array}{l}\text { Do you see that enhancing aesthetic qualities and } \\
\text { meaning through the adoption of conservation as } \\
\text { a basis for measurement and as a reference in the } \\
\text { maintenance process can enhance the visual } \\
\text { quality of Traditional Kut City Center? }\end{array}$ & & & \\
\hline 5 & $\begin{array}{l}\text { Do you see that improved visual connectivity by } \\
\text { preserving and reusing historic buildings and } \\
\text { places can enhance the visual quality of } \\
\text { Traditional Kut City Center? }\end{array}$ & & & \\
\hline 6 & $\begin{array}{l}\text { Do you think that enhancing Legibility \& } \\
\text { Imageability through the conservation process } \\
\text { rather than rebuilding the missing elements can } \\
\text { enhance the visual quality of Traditional Kut City } \\
\text { Center? }\end{array}$ & & & \\
\hline 7 & $\begin{array}{l}\text { Do you think that The combination of traditional } \\
\text { design and construction work in built structures } \\
\text { enhances the Individual Perceptual identity of } \\
\text { Traditional Kut City Center? }\end{array}$ & & & \\
\hline 8 & $\begin{array}{l}\text { Do you think that relying on the traditions of } \\
\text { architectural identity can enhance the Collective } \\
\text { Perceptual identity of Traditional Kut City } \\
\text { Center? }\end{array}$ & & & \\
\hline 9 & $\begin{array}{l}\text { Do you think that building buildings that take into } \\
\text { account the harmony and human feeling and } \\
\text { respect for local traditions enhances the } \\
\text { Silhouette \& Skyline of Traditional Kut City } \\
\text { Center? }\end{array}$ & & & \\
\hline
\end{tabular}

TABLE (2) assessment Questionnaire of

Encouragingpertse population to open small business horizons, making use of microcredit facilities, With attention to infrastructure and the improvement of houses and public spaces, so that the region more attractive. The region has been analyzed on this basis and it has been shown that:

Strength: The percentage of construction is the prevailing ratio Some places are available, which are attractive points and the most important landmarks in the city, such as Raouf Market and the Great Mosque of Kut.

Weaknesses: There are no open spaces or green spaces, leading to visual distortion. Not to deal with attractions and landmarks in the right way in terms of access roads and surrounding heights.

Opportunities: Open spaces, creating comfortable visual scenes, places of rest, entertainment and attention to the attractions of development and considered it the central point in the region providing visual and motor hubs that lead to the most important features of the region.

Threats: It is not possible to add open spaces as public buildings that are actually exploited and are not left to fit between neighborhoods and historical attractions.

\subsection{Findings and discussions}

Focusing on investment factors and strengthening the traditional kut city center of modern buildings (materials and modern technology), the city increased its morphological value and neglected the social side. The historic center is supposed to be of good quality. Return 69 of the experts bad urban visual quality may affect the privacy of the physical environment due to the deterioration of the physical elements in general. Thus being a major cause of urban transformations that may lead to an optical contamination of the urban landscape in general in traditional kut city center. The majority of traditional kut city center is a private property belonging to the residents, which restricts the ability of the urban designer during the redevelopment

The height of buildings is very varied, as there is no organized sky line for the region, and there is no dominant element in it, that is, it is random. The general construction situation is medium and needs to be reshaped, and the addition of open spaces to the urban fabric to reduce the mass hegemony. Thus, during the redevelopment of the region, all these things must be taken seriously. From SWAT analysis we will take a fundamental form of knowledge of the case study in the next paragraph:

\subsubsection{Heritage and Urban Maintenance:}

The experts went with the importance of architectural elements and the architectural heritage of the traditional city center of Kut, which represents the identity, privacy and aesthetic of the region.

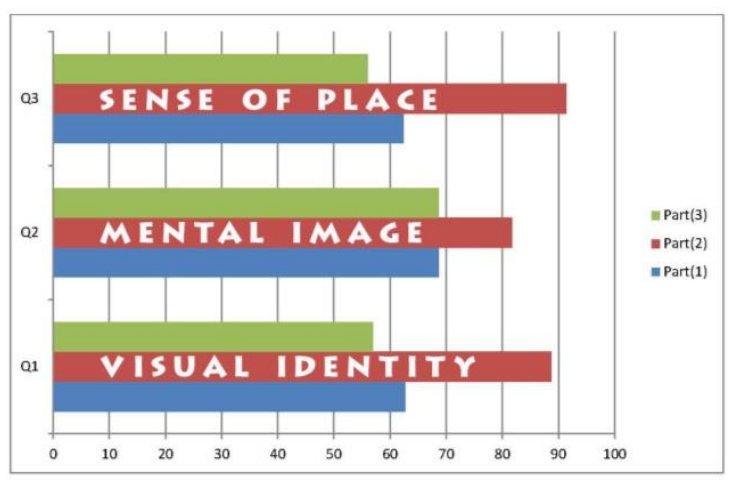

Figure (5) Heritage and Urban Maintenance

The experts have dindeked the concept of visual quality with the process of retaining property and architectural and heritage elements. They stressed 
the concept of sustainable conservation to include the process of maintaining and preserving origin along with taking into account the awareness of the values related to it and its relationship to its urban fabric and the characteristics of its community within it and its links with it. This concept includes Adaptive Reuse, which aims to adopt a suitable and appropriate new function for the site or historical origin that promotes its cultural, social and economic values.

\subsubsection{Enhancement of visual Value:}

Economic and social initiatives will enhance the morphological value of the traditional kut city center. These initiatives and improvements are effective tools in stopping some of the problems that accompanied the deterioration of these centers due to the time limitation and not keeping up with the technical and institutional progress of some of the historical city centers in the developed countries.

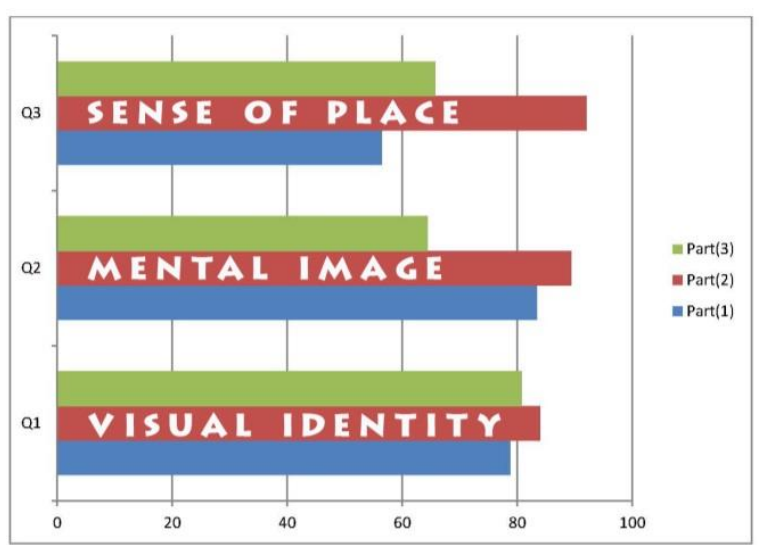

Figure (6) Enhancement of visual Value indicators

Here, most experts, while taking advantage of sustainability, have sought to achieve a better quality of the city center through:

- $86 \%$ Promotes and strengthening the vocabulary of the urban landscape of traditional kut city center and investing positively.

- $67 \%$ Social sustainability and activating the environmental and economic side of the urban environment.

- $\quad 77 \%$ revival of major events and focus on the main physical references in the urban landscape.

\subsubsection{Renewal and Urban Innovation:}

The process of involving citizens in planning and taking measures to promote individual initiative in the process of re-upgrading the plans and thinking solutions while keeping the population informed during the implementation phase of the project is one of the most positive steps.
The rehabilitation and use of open spaces available in the dense and complex fabric aims to raise the level of neglected spaces, and provide a healthy environment and contribute to the social and economic well-being of the population in the Old City is another positive step.

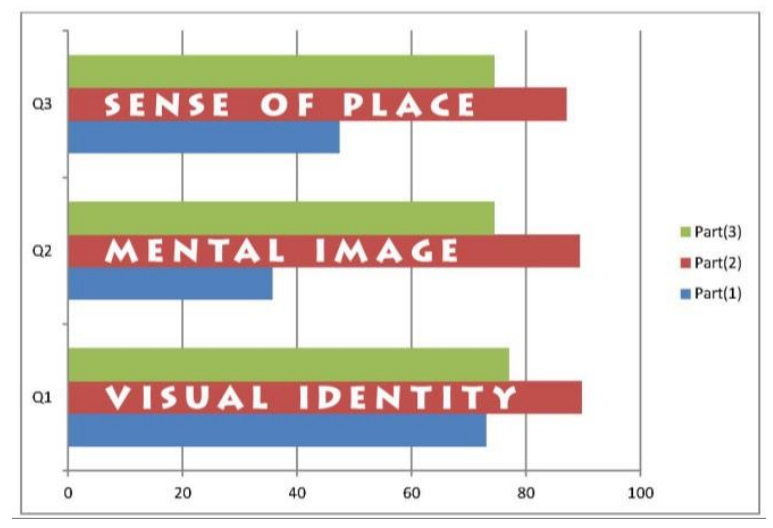

Figure (7) Renewal and Urban Innovation indicators

The move to finance housing in the city's traditional kut center is also a support for social life on the one hand and an enhancement of the built environment on the other. The experts believe that:

$74 \%$ support the moral and material heritage of the traditional kut city center.

$87 \%$ Achieve urban recovery and promote quality of life within the concept of reuse of adapted heritage.

$65 \%$ Add functional events that take into account the urban transformations and support the future of the traditional kut city center.

- With reference to the final results of the research, the third part has a high visual quality compared to other parts, so it can be said that the more attention to heritage and urban maintenance, the greater the visual value.

- The negative interventions have significantly affected the visual quality of the lack of interest in vertical indicators. Therefore, improving the visual value of new buildings does not necessarily have to be positive unless it is true.

- The three parts showed a decline in "renewed interest". However, markets and daily life has made the second part more visual quality. Ability to live are therefore important for raising visual quality.

Three benefits of the first good urban visual quality of the individual by improving the quality of life, The second to the community points of attraction to the concept of the local environment and 
the third to the city's future of spatial identity. Experts disagree on the quality of the intervention and agree on the importance of improving the quality of the urban visual quality.

Property owners and developers seek to make the most of their properties and benefit from the weakness of the local government in not complying with the laws. The local government also seeks to provide the appropriate services and infrastructure for the expansion of urban centers at the expense of the future vision or heritage of the city, with the absence of cultural awareness and heritage and urban culture of urban construction of the local government in most cases. While international organizations and NGOs seek to promote the values of belonging and activate local participation as much as possible. The need to control visual quality is very important as a result of this conflict over the city's structures.

\section{Conclusions and recommendations}

6.1.Visual Urban quality is the degree to which the environment can be clearly understood and represented morally and mentally in space and time by its users. And the degree to which this moral and intellectual structure is associated with the values and concepts of those people. The extent to which the physical environment, the capacities of sensory and mental individuals, and their cultural and civilizational structures are congruent.

6.2.sense of place varies from one observer to another and concept of identity based on the unique qualities, but there are basic constants in the experience of the place by different people.

6.3.supporting the process of development and providing financial support and implementing a comprehensive and balanced set of urban steps to preserve and improve the city comes from the very effectiveness of the local administration. The mechanisms and strategies are linked to trying to improve the quality of life of the residents of the traditional kut city center.

6.4.Attention to heritage elements can increase Visual Quality Of Traditional Kut City Center effectively.

6.6.Any enhancement of visual value must be subject to the three main and secondary indicators

6.5.The three parts showed a decrease in interest because Renewal \& Lan markets and daily life made the second part more visual quality.

Acknowledgements

I would like to thank Assistant Professor Sabeeh Lafta Farhan for his great effort in reviewing this paper. And I would also like to thank the students of the Department of Architecture, Wasit University, the fifth phase of their efforts in documenting and collecting information about the case study Of Traditional Kut City Center and surveying user opinions.

\section{References}

1. Introducing Urban Design: Interven tions and Responses, Clara Greed, Marion Roberts, Routledge, 2014.

2. Planning for Urban Quality: Urban Design in Towns and Cities, Michael Parfect, Gordon Power, LDR International, Psychology Press, 1997.

3. Matthew Carmona, The Design Dimension of Planning: Theory, content and best practice for design policies, John Punter, Routledge.

4. Lucy Natarajan, Design Governance: The CABE Experiment, Matthew Carmona, Claudio De Magalhaes, Routledge.

5. Streets and the Shaping of Towns and Cities, Michael Southworth, Eran Ben-Joseph.

6. Michael Corbett, Designing Sustainable Communities: Learning From Village Homes, Judy Corbett.

7. Assessing the Quality of Traditional Street in Indonesia: A case study of Pasar Baru Street, Arif Budi Sholihaha, Tim Heatha, Procedia - Social and Behavioral Sciences 234, 2016, Pages: 244 - 254.

8. Hamam Serag El Din, and others, Principles of urban quality of life for a neighborhood, (HBRC) Journal, Volume 9, Issue 1, April 2013, Pages 86-92.

9. Robert W. Marans, Quality of Urban Life Studies: An Overview and Implications for Environment-Behavior Research, Procedia, Social and Behavioral Sciences (35), 2012, Pages: 9-22.

10. Terry farrell, Urban design futures, Routledge, First published, 2006.

11. Ashwini Dhamankar Savannah, Urban Negative: A manual for Interstitial Spaces, Savannah College of Art and Design, 2017.

12. typological and morphological elements of the concept of urban space

13. Jan Gehl, Towards a fine city for people: public spaces public life-, Transport for London, GEHL ARCHITECTS, Urban quality consultants, Copenhagen, 2004.

14. Giuseppe Strappa and others, , ISUF, International Seminar on Urban Form, Rome, Italy, 2015.

15. Cliff moughtin, urban design: street and square, third edition, architectural press, 2003.

16. Martin Cook, The Design Quality Manual: Improving building performance, Building Research Establishment Ltd, 2007.

17. Michael Parfect, Gordon Power Planning for Urban Quality: Urban Design in Towns and Cities, 1997.

18. Matthew Carmona, Public places - urban spaces : the dimensions of urban design , 2nd ed, London, New York, 2010.

19. Kim dovey, urban design thinking: a conceptual toolkit, first published, an imprint of bloomsbury publishing plc, 2016.

20. Karen levine, the urban design hand book: techniques and working methods, London, 2003. 